\title{
Professor Constantin Dimitrescu-Severeanu Our Father and Contemporary (1840-1930)
}

\author{
Vasile Sârbu', Silviu Constantinoiu² \\ ${ }^{1}$ Faculty of Medicine, Ovidius University, Constanța, Romania \\ ${ }^{2}$ General and Esophageal Surgery Clinic, Carol Davila University of Medicine and Pharmacy, Bucharest, Romania
}

Corresponding author: Professor Vasile Sârbu

Faculty of Medicine, Ovidius Univeristy Constanta, Romania

E-mail: vasilesarbu_cta@yahoo.com
Received: 27.01 .2017 Accepted: 14.02 .2017
Constantin Dimitrescu-Severeanu is for us, contemporary Romanian surgeons, a monumental figure, perceived unjustly as old, originating in the museum's halls of national medicine, someone like Péan, Volkmann, Nélaton, Guyon, Langenbeck, Esmarch or Billroth to countries where they lived. Nationally, his figure has been somewhat pushed into the past by Thoma Ionescu the creator of the National School of Surgery. It is necessary to look by comparison between the brilliance and modernism of Thoma Ionescu and Severeanu`s efforts to get us out, like Moses from the egyptian slavery, out of the old ways of surgery without anesthesia, antiseptics, without asepsia, when opening of the womb, the chest and cranial cavity was not even thought by someone. Severeanu said that in 1864 and Thoma Ionescu returned to Bucharest from Paris after 30 years in 1895, when the big leap and synchronization with European medicine had been done.

His childhood in the Cioponea family, a hardworking family of 12 children, from Baltați (Mehedinți) is well known. Constantin came into the world on May 4, 1840, beginning primary school at the age of 13 in Turnu Severin, then at the age of 15 enrolling at Davila School and then performing his last 2 years as a student in Paris where he got his $\mathrm{PhD}$ in 1864 . He was then a secondary physician at Colentina Hospital, then primary physician at Colțea Hospital (1869), where there was a surgery department headed by Professor Nicolae Turnescu, the firs Dean (1869) of the newly founded Faculty of Medicine in Bucharest. At Colțea Hospital he will lead for 40 years (1870-1910) a department of surgery in which his great achievements will be done.

\section{Constantin Dumitrescu Severeanu and his genial intuitions}

His first impressive surgery took place at Colentina Hospital where he performed a chelotomy attended by his teachers, Turnescu, Polizu and Capşa and after that, as a sign of appreciation, Carol Davila invited him to dinner. His second impressive moment was the incision of a 
tonsillar phlegmon associated with trismus (through the space left free by the absence of a molar) saving the life of Carol Davila himself. Among all the physicians attending, Zita, Fotino, Severin, Turnescu, Patzelt, Marcovici, Fialla, Obedenaru and Severeanu, Davila chose him by writing on a piece "Si je dois guerir par mi". Obedenaru "Je prefer etre tue par Severeanu" (Obedenaru had taken responsibility to operate him). His brilliant intuition was given by the space that he chose for the insertion of the scalpel and by his anatomical accuracy. Equally brilliant was his intuition in introducing the microscope in cancer examination (1). After Charles Robin`s unattractive course in Paris, Severeanu bought a microscope and Kolliker`s book about the method of using it, visited a factory of microscopes and surgical instruments and then carried out a pathological examination of a tumoral biopsy.

Let's stop at another moment that tell us about Severeanu`s intuition. One day professor Severeanu found out that Dr. Nicholas Kernbach, with medical studies in Strasbourg, indicated the existence and use in Germany of a tool called "thermometer". With brilliant intuition, Professor Severeanu granted this an incredible value. Professor Dimitrescu-Severeanu was aware of the idea of some German doctors to know the true temperature of the body, which until then, was "measured" with the palm of the examiner. He knew about Wenderlich from Leipzig brochure (1868-1869), who spoke about the temperature change that appears in some diseases.

Professor Severeanu personally went to Leipzig to Professor Wunderlich in 1873, instructing himself on how to use a thermometer, and sensing the value of patient thermometrisation, brought it to romanian medicine (2).

Similarly, he sensed the importance of maintenance of the surgical instruments and the purchase of new instruments. When he was a young intern at Colțea Hospital he met the whetter Bubenicek, that sharped scalpels, and passing through Bucharest by chance he discovered Broehm and his friend Travizani shop, that came from Paris (Factory Charier) and Vienna (Factory Suer) which with 50 gold coins had opened a business: repair and maintenance of medical instruments. Professor Severeanu brilliant intuition led him to Carol Davila where he secured the employment of the two and set up a small workshop at Coltea Hospital. Broehm`s company will import surgical instruments, antiseptics and many others, especially from Schaffhausen factory for over 70 years.

He had the same intuition of the future when
Wilhelm Konrad Roentgen achieved his brilliant discovery made in December 1895. Well informed and good assessor of medical novelties, professor Severeanu took part in the Conference of $D$. Hurmuzescu, held it in 1896 at the Bridges and Roads School from Bucharest. Since March 1896, Eisenecker performed the first demonstrations of $\mathrm{X}$-rays and realized the image of a wallet with coins, a watch, a key and his own hand.

At a conference in June held by Hurmuzescu, professor Severeanu had X-rayed his own hand, but with eyes wide open to the future returned to Colțea Hospital where helped by Broehm and Eisenecker himself improvised a makeshift radiology apparatus in the Surgery clinic. It was a device "good enough that it can serve for the discovery of metallic foreign objects in the human body. "It would be recalled that Prince Ferdinand and Princess Maria exhibited their hands, thus yielding the first bone X-rays in Romania. A year had passed since the discovery of $\mathrm{X}$-rays when professor Severeanu, among the first in the world, in the report of the Surgical Service in 1896-1897 shows the first radiographs performed in our country. And in August 1897 at the International Congress of Medicine in Moscow presents the paper "Utilite des raysons X en chirurgie".

One of his students, D. Gerota will be our first radiologist and will lead the first radiology laboratory in our country, at the initiative of Professor Severeanu. Since 1906 the laboratory was entrusted to Gh. Severeanu (1878-1939) the professor's son, who became the first radiology professor in Romania. Within this direction, of intuition and inventiveness, the creation of new surgical instruments and amending of existing ones (3). For example, in 1870, he imagined two new porserfine models, the change of Pean forceps (new forceps very useful in hysterectomies - named Severeanu forceps), change of the Richelaut forceps and of the Dupuytren enterotome. With imagination, he conceived a spoon with which to reposition the humeral head in the glenoid cavity, in case of sprains, through a personal procedure. Professor Severeanu went to the Berlin Congress with a bladder probe designed by him, that was designed so as not to hurt the bladder and that had a trough which was used to cut through in hypogastric and perineal incisions.

As a student in Paris, Severeanu was deeply negatively impressed by the severe infections in hospitals and especially by their explanation by miasms and by surgeons that did not wash their hands, Pean performed surgeries dressed in a tuxedo that he considered cleaner than everyday clothes. 
Severeanu knew that Pasteur discovered what causes infections and Lister worked in aseptic conditions. This explains why Severeanu, who became a surgeon at Colentina and then at Coltea, decides to undertake a new journey in Europe.

In Budapest, in 1847, Ignás Fulop Semmelweis, a former student in Vienna, who was working as a physician in maternity, made an interesting observation: births in areas frequented by students who perform dissections on cadavers were more often accompanied by puerperal infections than the areas unfrequented by students. He proposed that midwifes wash their hands with a solution of calcium chloride (he believed it could neutralize a deadly poison that intoxicated the body of the mother); the mortality decreased rapidly (4).

It was nine years after his arrival from Paris (1873) and he wanted to know what was new in medicine. He wanted to personally see in Germany, Lister in England as well as other great surgeons and he wanted specially to see how they apply antisepsis apply and how they operate.

Reputed centers where he went were: Prague, Breslau (at Fischer), Leipzig (professors Wunderlich and Karl Thiersch). He learned about Lister's methods, about the thermometer and he wanted to visit the Schaffhauser dressings factory. Then a visit to Dresden and Berlin followed at surgeons Langenbeck and Adolf Bardeleben. Here he was particularly impressed by the young assistant Bergman who was interested of new surgical techniques. At Halle he met Volkmann then went to Kiel and Hanover. He went to Brussels and the Netherlands too.

The journey to Glasgow followed, where apparently, he did not arrive, from Dower going to Paris (Lister in 1873 was transferred to Edinburgh). It seems that he arrives in Glasgow on a later, different. In 1873 Lister demanded disinfection of the surgical instruments, hands, dressing, surgery rooms using fenic acid. His method is applied sporadically, only by some surgeons. Even in England, Simpson and Spens did not see favorably Lister's method even if they were separated only by some hospital walls. The method fascinated professor Severeanu who was horrified when he learned that in the Munich hospital gangrene comprised $80 \%$ of cases and the demolition of the hospital was in debate. 2 years after Severeanu's journey, in 1875 in Berlin, Lister will first communicate his method (although the results of his method were published in 1867 in the "The Lancet"). Lister's method will be adopted only at the end of his life (1827-1912). Arriving in Paris in 1873, Professor Severeanu found surgeons who mocked
Lister's discoveries. Let's remember that wool dressing was discovered in 1870 by Alphonse Guerin. Severeanu immediately adopted it during his visit. Antisepsis will be adopted not only by Severeanu in 1873 but after the Berlin Congress by Langebeck, Esmarde, Bruns, Volkmann, Billroth and Thiersch.

After his journey in 1873 Severeanu introduced wool bandages instead of lint ones and started using dressings with hydrophilic cotton wool, hydrophilic gauze and. He will later use gloves and mask also anticipated by Assaky and T. Ionescu.

As regarding anesthesia, Severeanu used chloroform general anesthesia introduced in practice in 1847. The first general anesthesia using a mask was performed in 1846, in Boston, by William Morton, using ether as the volatile gas, for a tooth extraction. But he also used local and spinal anesthesia (4).

Severeanu being aware of Claude Bernard's recommendation of combining morphine with chloroform, recommended morphine injections minutes before administering chloroform. Nowadays, patients' premedication has an importance few dreamed about in that time. On December 29, 1899 Severeanu performed our country first spinal anesthesia, helped by his resident D. Gerota.

Tuffier and Chaput in Paris, also in 1899 introduced spinal anesteshia and have made an enormous propaganda in its favour. Severeanu used cocaine hydrochloride as they did but its toxic effects and dangers made him circumspect after the first 27 cases, the advocating for general anesthesia.

He was aware of Thoma Ionescu's success with upper spinal anesthesia by stovainisation, in Romania but also in Britain and the US, but remained reserved of the method, but this does not mean that he did not cherished him. Severeanu urged Iancu Jianu to learn the method and left him the freedom to practice it. Toma Ionescu saw Severeanu as a sacred monster of Romanian surgery and in 1898 appointed him the first President of the Romanian Society of Surgery, inviting him to chair its constituent session (5).

\section{Severeanu and his contribution to the development of Romanian and universal surgery}

Severeanu, a progressive surgeon with a formidable sense of new and sustainable operations, having devised anesthesia, antisepsis and sterility tackled visceral surgery with great success.

He performed the first laparotomies in romanian surgery, the first splenectomy for a giant postmalaric spleen, first vaginal and abdominal hysterectomies, thyroid surgery, resection of the 
upper jaw, appendectomies, gastro-enteral anastomosis in ulcerative stenosis, orthopedic surgery, rhinoplasty, tracheostomy, etc.

What gave him immense notoriety was "arterial catheterization", first trombendarterectomy of universal surgery, applied to a blunt ischemic thigh. His intuition represented the starting point of contemporary blood flow restoration and explorations in vascular surgery. In the same category, we must mention the over the edge stitch, surget thread, wrongly named Doyen, which is widely used in modern surgery including laparoscopic, plastic and cardiovascular surgery. It was once again a world first. "Suture of the abdominal wall" is again an international priority, which applies to all operating theaters today, communicated today in Berlin at the German Surgeons Congress in 1887. He developed it to reduce the number of postoperative hernias. What is amazing and makes him monumental in our eyes is the fact that his surgeries passed the test of time. How to perform an organ transplant or vascular or digestive bypass without the surget suture.

The surgery for cleft lip, the only one named "the Severeanu surgery" gave the measure of his talent and surgical logic because he was the first who dissected the myo-mucocutaneous plans and sutured them separately to achieve both esthetic results and high functionality. Logical thinking led him to recommend and carry out "Decapitation of the femoral head in irreducible hip sprains" or apply a new method for reducing old glenohumeral dislocations.

\section{Professor Severeanu`s virtuosity}

Professor Severeanu introduced intradermal suturing in surgery and other aesthetic sutures; he urged all young surgeons to operate in cleavage plans to make small pedicles, only with Pean forceps, not Kocher, to clamp only the vessel that bleed. The first thing he teaches surgeons was how to ligate a vessel, uncrossed, neither too tight nor too loose. He often performed difficult operations such as resection of the upper jaw or facial cancers, or bronchial foreign body extraction, rhinoplasty, surgery for facial malformations, vascular surgery, vascular reperfusion, and so his virtuosity was visible and consecrated. He performed surgery without haste, but avoided unnecessary steps and gestures, making surgeries fast and smooth.

\section{Severeanu, the character man}

There are many elements which present us him as righteous and correct man, including the invitations he received as a doctor and refferee at many duels, as an expert in leading journals, as founder of settlements needed by the Romanian people of his time (First Health Home, first Vaccines Institute, first Institute of Sisters of Charity "St. Elizabeth", 1879 etc). He was the first president of the Romanian Society of Surgery where he along with T. Ionescu imposed a style and model of debate that continues today as if Severeanu is present with us. He was elected the first president of the Society for the History of Medicine in 1829 founded by the initiative of his intransigent pupil V. Gomoiu, fought with medical charlatans of the time, published books (lessons) of surgery required by students, went with dignity to famous Congress as those of Berlin (four times), Paris (several times), Lyon, Rome, Vienna, Moscow, where he and $\mathrm{T}$. Ionescu presented the achievements of our national surgery.

In old age, when uncovered in his attic the Mason apron he frankly confessed that "so said Davila" who was also a Mason, as Napoleon-III who protected Davila, Cuza or Alecsandri, Carol I, Bratianu and many other Masons. He was a friend and had distinct relationships with the great lawyers of the time (Vernescu, Costa-Forn Boerescu) with great performers (Haricleea Darcle, Elena Teohari, royalty (Carol Ferdinand) with Kogalniceanu who died in front of him from an intervention at Guyon's Clinic, with paimters such as Tattarescu, Th. Aman, Nicolae Grigorescu and especially Ion Andreescu who loved him and who died of tuberculosis after a life of misery and poverty. He suffered at the undeserved death of personalities such as king Ferdinand (undetected rectal cancer), I.C. Bratianu (accidental carotid injury) and Vasile Parvan unsuccessfully operated, when Severeanu exclaimed "why did Angelescu do it?".

When Turnescu, his teacher at the School of Davila was in trouble, Severeanu did not criticize him and when he was promoted as professor he did not take the clinic but instead created two clinics.

And when he emerged from Lille where he served as Assistant Professor, Gheorghe Assaky (1886), made famous by his brilliant work, "The suture of nerves at distance" Severeanu joined the group of those who demanded that he must pass an exam in order to become professor. He refused, believing that he had passed a more signifcant exam in Lille, which was more important than the one in Bucharest. Finally, through an error immense, Assaky was disbanded as well as his Institute and so he was forced to go back to Paris, 
although Bratianu accepted Babes, Kalinderu and Assaky as professors by a special law (1897). A new law cut the Institute's budget and Assaky was practically forced out of education.

Severeanu joined the unjust denigrators' campaign. Medical students from Bucharest together with the Medical Students Society and its President, Gh. Marinescu remained with Assaky along with many teachers and so have restored and reinstated him, thus defeating the Romniceanu group Romniceanu (also through a special law). Assaky will die young, and Severeanu will reassess and make a unique gesture to his fellow and recognize that he was wrong and would reject what he had done.

A motivation in a way that will be available over decades and even today: a great man, even greater teacher can make mistakes in relationships with his colleagues. And he erred because what he meant was that students that returned from studies in the west ought not to replace the generation that preceded them, in this case, Davila's generation. And it was not his only admitted error, because one day he presented at the Romanian Society of Surgery a resounding failure: the death of a patient, that the necropsy proved had acute appendicitis and that was declined surgery both by him and Thoma Ionescu. This has opened a great way of communicating own professional failures that it will further be illustrated by many valuable surgeons.
He was a happy man, traveled to many countries, took great dignity, had 4 children, shocked contemporaries by professionalism, left the department and clinic dignified, raised pupils of great prestige; he was among the aristocracy of the era, around Carol I and Ferdinand and great artists and writers. He was bright but modest, did not appropriate its position, went with pleasure and visited all realms of our homeland. He died of a brain haemorrhage after a lecture at the Athenaeum in 1930, four years after Thoma Ionescu, which burned brighter, but that was not a contemporary of the great progress in the second half of the nineteenth century and has not sensed those operations that were not perishable, maybe because he was too great of an anatomist while Professor Severeanu was too great of a surgeon.

\section{References}

1. Angelescu N. Constantin Dimitrescu-Severeanu (1840-1930). Chirurgia (Bucur). 2006 Jan-Feb;101(1):9-11. Romanian

2. Jianu I, Bercus C. Constantin Dimitrescu Severeanu. The age and the opera. Craiova; 1979.

3. Suceveanu CD. From my memories (1853-1929). Bucharest (taking care of C. Rezachevici); 2008.

4. Constantinoiu S. Istoricul Chirurgiei. În Manual de Chirurgie pentru studenți, sub redacția Eugen Brătucu. Bucuresti: Ed. Universitară Carol Davila; 2009. p.1-25.

5. Sarbu V. Pages from Romanian surgery history. Bucharest: Acad. Rom. Ed.; 2002. 